\title{
Characterization of Friction and Wear Behavior of Friction Modifiers used in Wheel-Rail Contacts
}

\author{
M.A. Oomen ${ }^{1}$, R. Bosman ${ }^{1}$, P.M. Lugt ${ }^{1,2}$ \\ ${ }^{1}$ University of Twente, Laboratory of Surface Technology and Tribology, PO Box 217, 7500 AE, Enschede, The Netherlands \\ m.a.oomen@utwente.nl \\ r.bosman@utwente.nl \\ p.m.lugt@utwente.nl
}

${ }^{2}$ SKF Research and Technology Development, Nieuwegein, The Netherlands

\begin{abstract}
Reliable traction between wheel and rail is an important issue in the railway industry. To reduce variations in the coefficient of friction, so-called "friction modifiers" (carrier with particles) are used. Twin-disk tests were done with three commercial friction modifiers, based on different compositions of carrier and particles, to characterize their friction and wear behavior. It is shown experimentally that the influence of the carrier cannot be neglected just after application and very low (0.01-0.05) frictional values are observed in a fully flooded situation. However, starvation occurs quickly and friction values will become relatively stable at an intermediate level around $\mu=0.2$ until the friction modifier is consumed and a new dose is required. After the carrier is pushed out of the running track the particles in the contact dominate the tribological performance. The level of friction is a function of total rolling distance, effective sliding length and sum velocity. The most dominant factor depends on the friction modifier and the working mechanism for friction stabilization. It is also shown that the wear rates during tests do not depend significantly on slip, which makes it possible to predict wear behavior. Wear rates are dependent on the type of friction modifier used.
\end{abstract}

\section{INTRODUCTION}

In the railway industry, friction between the wheel and rail is an important topic. Throughout all railway systems, friction values vary from low $(\mu \approx 0.01)$ to high $(\mu \approx 0.6)$ (Iwnicki, 2006; Popovici, 2010), mainly due to the open nature of the system, which makes it very difficult to control the interfacial layers that have a large impact on the

Oomen, M.A. et al. This is an open-access article distributed under the terms of the Creative Commons Attribution 3.0 United States License, which permits unrestricted use, distribution, and reproduction in any medium, provided the original author and source are credited. values for friction and wear. At both extremes, there are undesirable effects: at low values, trains lose traction, introducing skidding and damage to the track and safety issues. At high friction, catastrophic wear, accompanied by flaking and spalling of the rail can be expected. To avoid these extremes, ideally the friction coefficient should be maintained at an intermediate range between $\mu=0.2$ and $\mu=0.3$ (Oscar Arias-Cuevas, 2010; Li \& Arias Cuevas, 2009), preferably with low wear characteristics. If a stable and controlled system can be achieved, which results in a predictable behavior of the rail system, not only reliability and availability can be improved, but also monitoring and scheduling maintenance becomes straightforward. Stabilizing friction can be done by introducing so-called "Friction Modifiers"(FM). FMs are in general suspensions of solid particles in a carrier. The carrier can vary from water, oil or grease to a solid state form (Chiddick, 1994; Cotter, 2004; DeBlase et al., 2013). The main working mechanism of these FMs is to dominate the interfacial layers present at the wheel-rail interface, sometimes indicated as the third body (Gallardo-Hernandez \& Lewis, 2008; Godet, 1984; Lu, Cotter, \& Eadie, 2005; Popovici, 2010). They are applied onto the rail or wheel surface and are subsequently spread out by passing trains. The first wheels that pass over the newly applied FM will experience a thick layer of fully formulated FM, which is quickly reduced by passing wheels that push the carrier and part of the particles out of the contact, leaving a thin layer on the tracks, mainly consisting of solid particles (Galas, Omasta, Krupka, \& Hartl, 2016). To stabilize the friction, using a FM, within a predefined interval is problematic. Stabilizing friction will not only contribute to safer operations but will also reduce noise, by preventing squeaking while cornering, which is mainly caused by stick-slip (Dhoke, 2013; Eadie, Santoro, \& Powell, 2003). Initially lower coefficients of friction are observed. After a considerable amount of passages, the friction gradually increases 
towards values corresponding to the unlubricated case by consumption of the FM. Galas et al. (Galas et al., 2016) showed that the level of friction depends on the amount of FM supplied to the contact and showed that for high entraining velocity and fully flooded conditions friction will be low due to full-film lubrication. It is currently not known which particles stay in the running-track and what their exact contribution to the obtained friction is. To get a better understanding, the first step is to understand the lubrication mechanism behind the observed friction. Wear in wheel-rail contacts under both conditioned (lubricated) and dry conditions has been given a considerable amount of attention in recent years (Hardwick, Lewis, \& Eadie, 2014; Lewis \& Dwyer-Joyce, 2004; Olofsson, Zhu, Abbasi, Lewis, \& Lewis, 2013). The main goal of these studies was to derive empirical relations to predict wear levels, however there is only a limited amount of information available in open literature dealing with the underlying frictional mechanism considering the size, shape and material of the particles in the contact (Galas et al., 2016). The initial phase, i.e., the time after applying the FM on the rail/wheel, can be well reproduced on a twindisk setup. However, the steady state condition, where the FM is spread out over the rail, is challenging to reproduce. The main limitation of a twin-disk test in this respect is the fact that the disks are in repeated contact. This prevents the FM from spreading out over a large surface area as in the real application. However, by setting the test conditions appropriately, representative results can be obtained (O. Arias-Cuevas, Li, Lewis, \& Gallardo-Hernández, 2010; Hardwick et al., 2014). This problem can be further minimized by providing the contact with a very limited initial amount of FM. Additionally, instead of using a fully formulated FM, solid-particle pastes with a high concentration of particles can be used. This simulates a realistic situation, where the carrier has been spread out and squeezed out of the contact.

\section{EXPERIMENTAL METHODS}

To be able to identify the dominating frictional mechanism, first the type of particles in the FMs will be determined using X-Ray Fluorescence (XRF) measurements. The size and shape of the particles are measured using a Keyence VHX 5000 digital microscope.

The friction and wear behavior of the FMs is measured using an in-house developed HOrizontal twin-DIsk Machine (HODIM) at the University of Twente, see Figure 1. In this machine, the bellows provides the normal load on the disks. The disk and the motor on the right side in the figure are mounted on a frame supported by several elastic hinges, consisting of a set of leaf springs. These hinges have a limited stiffness in torsional direction compared to the normal direction allowing the frame in which the motor is mounted to rotate. This causes a difference in the normal loads measured in the force transducers (see Figure 1), which in turn gives a measure for the friction present in the disk-disk contact. This design ensures that the internal friction of the motor and gear assembly are not included in the friction signal. The operational specifications of the HODIM can be found in Table 1 and the test conditions used in the current study are given in Table 2 . The contact load and used slip to roll ratio were calculated from representative wheel-rail conditions that are present in the Dutch railway system. The load carried by one wheel is approximately $80-100 \mathrm{kN}$, resulting in an average contact pressure between 0.51 and $0.55 \mathrm{GPa}$ (Beagley \& Pritchard, 1975; Popovici, 2010). The sum velocity used is $0.2-10 \mathrm{~m}$ $\mathrm{s}^{-1}$ and is lower than that of the wheel-rail contact (up to 80 $\mathrm{m} \mathrm{s}^{-1}$ ), but it is regarded as a sufficient range, as the friction behavior doesn't change significantly between 3 and $10 \mathrm{~m}$ $\mathrm{s}^{-1}$. This means that the time-scale of the phenomena measured on the disk machine can be different than that experienced in the field. However, the setup does make it possible to study the basic mechanisms under realistic conditions.

\begin{tabular}{l|l}
\hline Disk material & $\begin{array}{l}\text { Bearing steel (AISI } \\
52100)\end{array}$ \\
\hline Hardness disk [HV] & 800 \\
\hline Disk radius [mm] & 62 \\
\hline Crowning radius [mm] & 500 \\
\hline Sum velocity range [m.s $\left.{ }^{-1}\right]$ & $0.2-20$ \\
\hline $\begin{array}{l}\text { Maximum normal force } \\
{[\mathbf{k N ]}}\end{array}$ & 10 \\
\hline Slip accuracy [\%] & 0.15 \\
\hline Motor power [kW] & 10 \\
\hline
\end{tabular}

Table 1. Specifications HODIM

\begin{tabular}{l|l}
\hline Normal force $[\mathbf{N}]$ & $4.4 \times 10^{2} \pm 5 \mathrm{~N}$ \\
\hline $\begin{array}{l}\text { Mean contact pressure } \\
{[\mathrm{GPa}]}\end{array}$ & 0.53 \\
\hline Velocity range $\left[\mathrm{m.s}^{-1}\right]$ & $0.2-10$ \\
\hline
\end{tabular}

Table 2. Test settings HODIM

During (de-)acceleration additional friction/traction is required and typically an increase in slip is observed, which is estimated to be around 5\% during normal operation (Gallardo-Hernandez \& Lewis, 2008). Here slip is defined as:

$$
S=\frac{2 * v_{\text {dif }}}{v_{\text {sum }}} * 100 \%
$$

where $\mathrm{v}_{\text {dif }}$ is the sliding velocity between the wheel and rail and $v_{\text {sum }}$ is the sum velocity (Popovici, 2010). In this study 


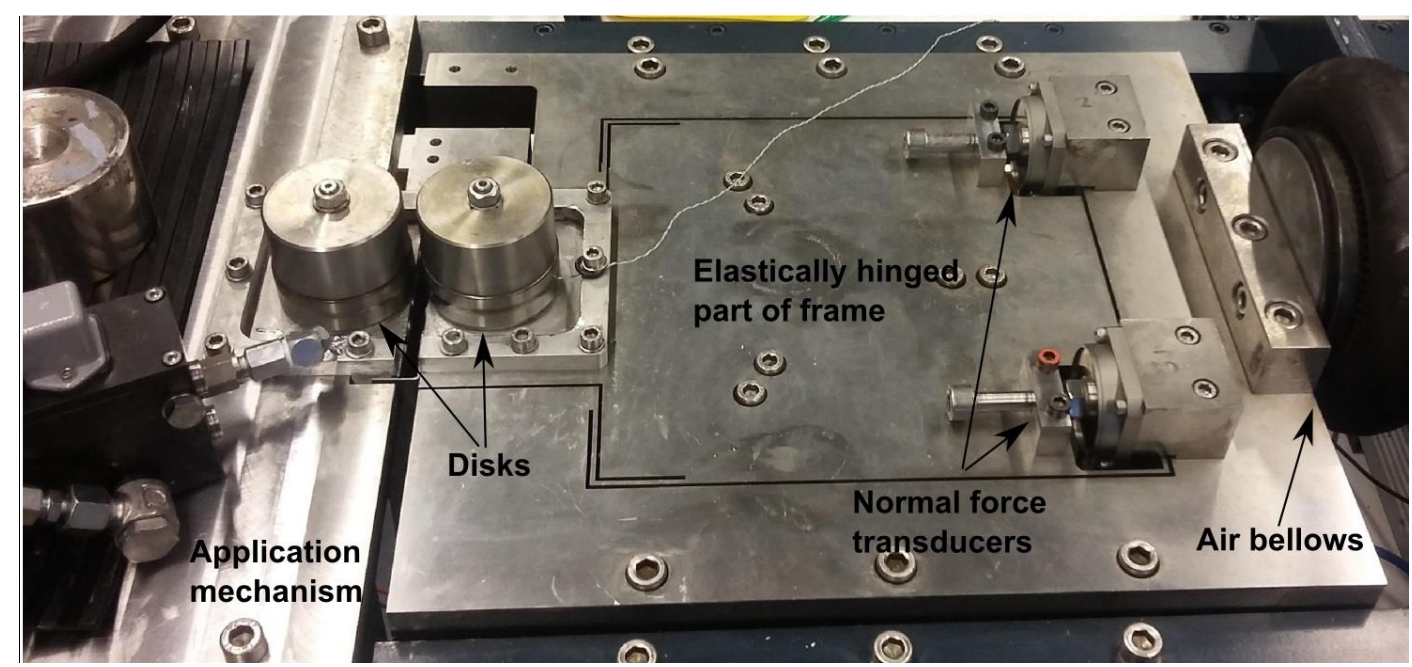

a) HODIM set-up as used during testing

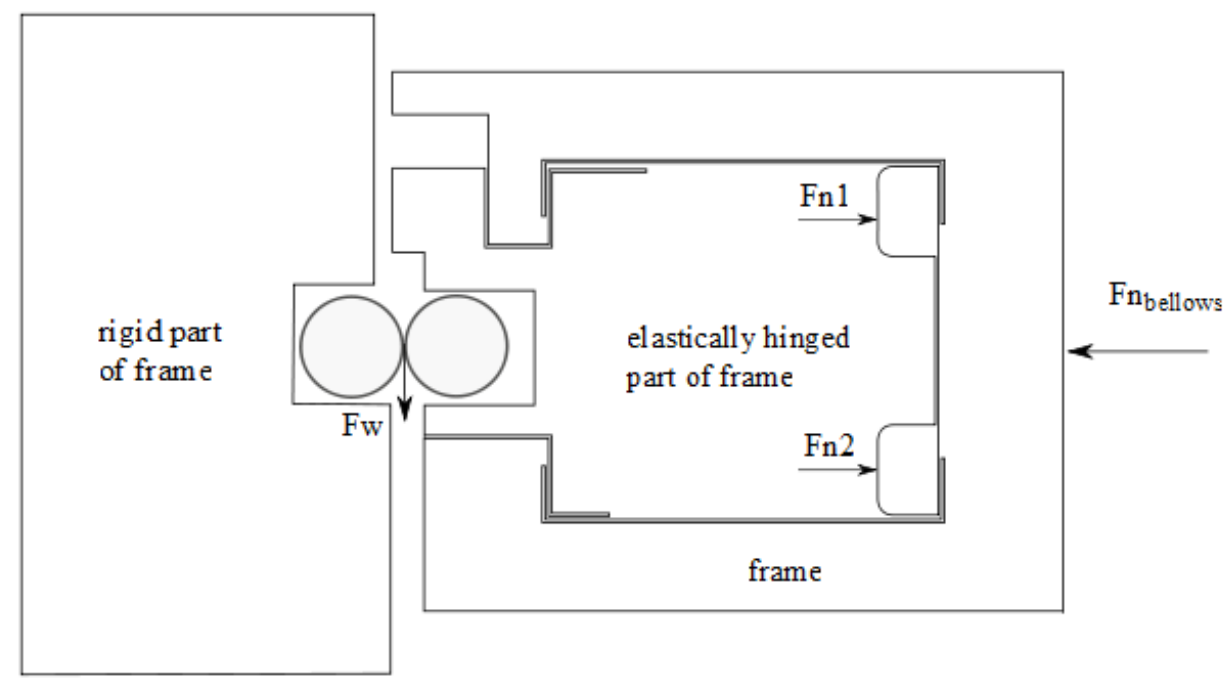

b) Schematic representation to illustrate the working principle

Figure 1. The HOrizontal twin-DIsk Machine (HODIM) used at the University of Twente

slip values up to $11 \%$ are used, because these slip values may occur during emergency braking where traction becomes even more crucial.

In twin disk tests with fully formulated FM, the contact was continuously supplied with FM ensuring abundant lubricant was present at the inlet at all times. However, in the real application only a limited amount of FM is available and most probably during spreading and usage the particles are disintegrated, pushed out of the contact etc. This causes a 'consumption' of the FM and the level of friction becomes a function of time. To investigate this effect tests were done where $40 \mu \mathrm{L}$ of FM was applied and where the disks were subsequently running for an hour at a constant sum velocity of $2 \mathrm{~m} \cdot \mathrm{s}^{-1}$ without actively replenishing the contact. This volume of $40 \mu \mathrm{L}$ of FM is similar to the volume applied to the wheel-rail contact in practice, where $50-100 \mu \mathrm{L}$ is applied every 12 to 60 seconds.

Twin-disk tests were also done with concentrated pastes derived from the FMs through centrifuging. These pastes were tested to mimic conditions where the carrier is removed from the FM layer on the rail/wheels which is expected to occur in practice after being overrolled several times. It is likely that the derived paste still contains a substantial fraction of carrier. However, measurements with a paste will at least be closer to the conditions experienced after longer times on the track. Stribeck curves were obtained at three (approximate) slip values $(0.5 \%, 5 \%$ 
and $11 \%$ ) to investigate the effect of slip on friction as well as the sum velocity. The exact values are given in Table 3 . Friction and wear are typically either dominated by adhesion or by abrasion which will be strongly dependent on the shape, material and size of the particles. Especially for abrasion the slip value will have an influence as this can cause a transition from a more pitting wear (overrolling of the particles) to scratching (ploughing/cutting) (Fang, Kong, Su, \& Zhou, 1993; Sin, Saka, \& Suh, 1979).

\begin{tabular}{l|l|l|l}
\hline & $\begin{array}{l}\text { Low slip } \\
\text { value [\%] }\end{array}$ & $\begin{array}{l}\text { High slip } \\
\text { value [\%] }\end{array}$ & $\begin{array}{l}\text { Extreme slip } \\
\text { value [\%] }\end{array}$ \\
\hline $\begin{array}{l}\text { Friction } \\
\text { Modifier }\end{array}$ & $0.58 \pm 0.06$ & $4.89 \pm 0.03$ & $10.87 \pm 0.07$ \\
\hline Particle paste & $0.48 \pm 0.08$ & $4.86 \pm 0.14$ & $10.92 \pm 0.02$ \\
\hline Unlubricated & $0.72 \pm 0.03$ & $4.73 \pm 0.14$ & $11.30 \pm 0.33$ \\
\hline
\end{tabular}

Table 3. Slip measured during tests with Friction Modifiers and particle pastes and in unlubricated conditions.

It is assumed that friction modifier in the wheel-rail contact will be consumed over time and to check the rate of consumption and if friction stabilizes, tests were done at all values of slip with $40 \mu \mathrm{L}$ of FM for an hour at a constant sum velocity of $2 \mathrm{~m} . \mathrm{s}^{-1}$.

\section{MATERIALS}

The general properties of the three commercially available FMs are given in Table 4. All tested FMs are suspensions of a synthetic ester oil based carrier with dispersed solid particles. The letters $\mathbf{C}, \mathbf{S}$ and $\mathbf{A}$ stand for the main solid component of the FMs: Copper, Silica and Aluminum. Finally, the approximate volume fraction of solids in the FMs can be determined after centrifuging and washing and these are also given in Table 4.

\section{RESULTS AND DISCUSSION}

\subsection{Friction Modifier characterization}

To understand the working principle behind the different FMs the first step is to investigate their components in more detail. To do so, chemical and optical characterization were done to obtain the chemical elements present and an indication of the particle size. The chemical composition obtained using XRF, in element percentages, is listed in Table 5. Additionally, the results from the optical microscopy are shown in Figure 2.

For all FMs, the size of the majority of the individual particles is in the order of $1 \mu \mathrm{m}$, except for some larger copper particles. For FM C, the copper present can be clearly seen in Figure 2a, as can be determined from the color of the large particles. Other components obtained from the XRF-results, like silicon and aluminum, cannot be identified conclusively in the images. According to product specifications, graphite is also present in FM C, this can however not be identified by XRF measurements as it is included in the general organic residue. Nevertheless, as shown in Figure 2a, the dark particles which are present in the residual after drying do indicate the presence of graphite. For FM S, two types of particles can be identified; $\mathrm{Al}$ and $\mathrm{Si}$, see Figure 2b. For FM A, see Figure 2c, the particles are aluminum and copper. The average diameter of the individual particles present in each FM was measured using image processing software ImageJ ( $\mathrm{T}$. Ferreira, 2012) and is given in Table 6. The standard deviations were determined based on a lognormal distribution of the particles. Based on the copper and graphite present in FM C and the copper and aluminum present in FM A, it is expected that these FMs produce a protective layer on the surface and will show adhesive frictional behavior to stabilize friction. The presence of the harder silica in FM $\mathrm{S}$ indicates an abrasive friction mechanism for friction stabilization.

\begin{tabular}{l|l|l|l}
\hline & FM C & FM S & FM A \\
\hline Color & Black/grey & Dark grey & Silver/grey \\
\hline Physical Appearance & Oil based with particles & Oil based with particles & Oil based with particles \\
\hline $\begin{array}{l}\text { Dynamic viscosity } \\
\text { base oil at } \mathbf{4 0}^{\circ} \mathbf{C}[\text { Pa.s] }\end{array}$ & $0.039^{*}$ & $0.033-0.042$ & 0.037 \\
\hline $\begin{array}{l}\text { Density friction } \\
\text { modifier }\left[\mathbf{k g} / \mathbf{m}^{\mathbf{3}}\right]\end{array}$ & 1150 & 1200 & 1150 \\
\hline Base oil & Synthetic ester & (Synthetic) Ester & (Synthetic) Ester \\
\hline Solids & Copper, Graphite & Silica, Aluminium & Aluminium, Copper \\
\hline Volume fraction solids & $0.56^{*}$ & $0.54^{*}$ & $0.26^{*}$ \\
\hline
\end{tabular}

*Experimentally determined

Table 4. Friction modifier properties 


\begin{tabular}{l|l|l|l}
\hline & FM C & FM S & FM A \\
\hline Element & {$[\%]$} & {$[\%]$} & {$[\%]$} \\
\hline organic residue & $(79.0)$ & $(86.0)$ & $(36.0)$ \\
\hline $\mathrm{Cu}$ & $\mathbf{1 2 . 0}$ & & 8.9 \\
\hline $\mathrm{Si}$ & 6.0 & $\mathbf{6 . 2}$ & 0.8 \\
\hline $\mathrm{Al}$ & 2.0 & $\mathbf{6 . 0}$ & $\mathbf{5 3 . 0}$ \\
\hline $\mathrm{Fe}$ & 0.4 & 0.2 & 0.1 \\
\hline $\mathrm{P}$ & 0.4 & 0.2 & 0.4 \\
\hline $\mathrm{Mg}$ & 0.3 & & \\
\hline $\mathrm{Ca}$ & 0.1 & & 0.1 \\
\hline $\mathrm{Zn}$ & 0.1 & & \\
\hline $\mathrm{S}$ & $<0.1$ & 0.4 & \\
\hline $\mathrm{K}$ & & 0.7 & \\
\hline
\end{tabular}

Table 5. Components of FMs and element percentages from XRF-measurements

\begin{tabular}{l|l|l}
\hline & $\begin{array}{l}\text { Particle size } \\
{[\mu \mathrm{m}]}\end{array}$ & $\begin{array}{l}\text { Median } \\
{[\mu \mathrm{m}]}\end{array}$ \\
\hline FM C graphite & $1.5 \pm 1.3$ & 1.0 \\
\hline FM C copper & 21.7 & 10.2 \\
\hline FM S silica & $1.1 \pm 0.8$ & 0.5 \\
\hline FM S aluminium & $2.0 \pm 1.5$ & 1.2 \\
\hline FM A aluminium & $1.1 \pm 0.9$ & 0.6 \\
\hline FM A copper & $3.8 \pm 2.2$ & 3.6 \\
\hline
\end{tabular}

Table 6. Average particle size of different elements in the FMs

\subsection{Friction performance}

\subsubsection{Fully Formulated Friction Modifier}

Friction performance is quantified by means of Stribeck curves for the FMs. Fully formulated FMs were tested at $0.5 \%, 5 \%$ and $11 \%$ slip in fully flooded conditions varying the sum velocity on the twin-disk setup. The tests consisted of three cycles increasing and decreasing the sum velocity from 0.2 to $10 \mathrm{~m} \mathrm{~s}^{-1}$. During the first cycle the surfaces will run-in, so the Stribeck curves shown in Figure 3 are the average results of the second and third cycle. In Figure 3, the velocity is plotted on a logarithmic scale for clarity. For all FMs friction generally decreases with increasing velocity, which is ascribed to the increasing entrainment of the fluid carrier into the contact with increasing velocity. Mixed lubrication occurs where the load is only partly carried by the base oil and where friction is less sensitive to slip (Johnson, Greenwood, \& Poon, 1972). As can be seen in Figure 3, all FMs show a transition from a Mixed Lubrication (ML) to an Elastohydrodynamic Lubrication (EHL) regime at sum velocities between 1 and $3 \mathrm{~m} . \mathrm{s}^{-1}$, which means that the two surfaces are completely separated by a lubricant film. Overall, friction is low, especially at higher sum velocities $(\mu<0.02)$ for all FMs. As mentioned earlier, the current test conditions simulate riding over freshly applied FM and from the results it can be concluded that a safety risk exists when excessive FM is applied. However, it is expected that these fully flooded conditions only exist for a split second and that the carrier will be squeezed out of the contact during first passing, leading to starved lubrication and eventually "dry" contacts (Van Zoelen, Venner, \& Lugt, 2009). Furthermore, it is expected that normally also the thickness of the deposited solid-particle layer will be reduced over time. This effect is referred to as "consumption of the FM".

To simulate this effect of consumption of the FM by passing wheels, twin-disk tests were done at $0.5 \%, 5 \%$ and $11 \%$ slip with $40 \mu \mathrm{L}$ of FM applied to the contact after which friction was measured for one hour. Additionally unlubricated tests were done and are used as a reference. The results are shown in Figure 4 and indeed show that there is consumption of the FM over time. For all values of slip, friction in the unlubricated conditions quickly increases to values between 0.3 and 0.4 , after which it stabilizes. For FM C, the friction increases to values of around $\mu=0.4$ for all slip values, indicating a transition to dry sliding. This transition happens sooner when the slip rate is increased, which means that $\mathrm{FM} \mathrm{C}$ is consumed faster at a higher slip rate. A possible explanation is the relatively soft graphite used in FM C, which will be worn off quite easily. FM S shows very stable friction values of around $\mu=0.17$ for $5 \%$ slip and $11 \%$, which indicates a very good stabilization. As the particles in FM S are hard and abrasive, they do not wear as a function of sliding, but once embedded into the surface stay in the contact, and thus a reduced effect of the sliding distance can be expected. FM A shows a stable friction coefficient of $\mu=0.13$ and $\mu=0.25$ at 0.5 and $5 \%$ slip, respectively. However, a gradual increase in friction is observed and the rate of increase appears to be a function of the slip ratio. At extreme slip rates an increase to unlubricated friction is observed.

In general, it takes a significant amount of time to reach the desired friction values between $\mu=0.2$ and $\mu=0.3$ and in some tests friction stabilizes already at a level of friction lower than $\mu=0.2$. However, as the 2 -disk tests are done with a repetitive contact, it is assumed that this level of friction will be achieved much faster for the wheel-rail contact; friction modifier will be distributed over a longer distance without reintroduction of friction modifier to the contact reducing the amount of friction modifier in the contact at a much higher rate. 


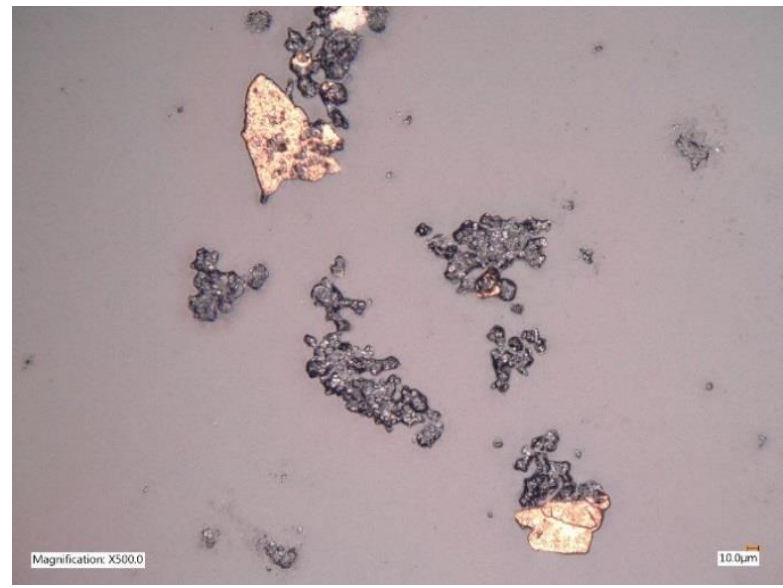

a) FM C particles, 500x magnification

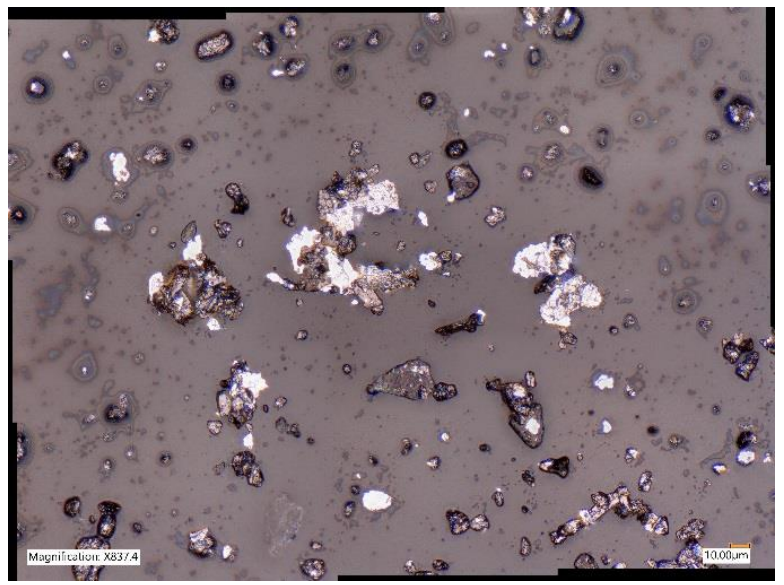

b) FM S particles, 837x magnification

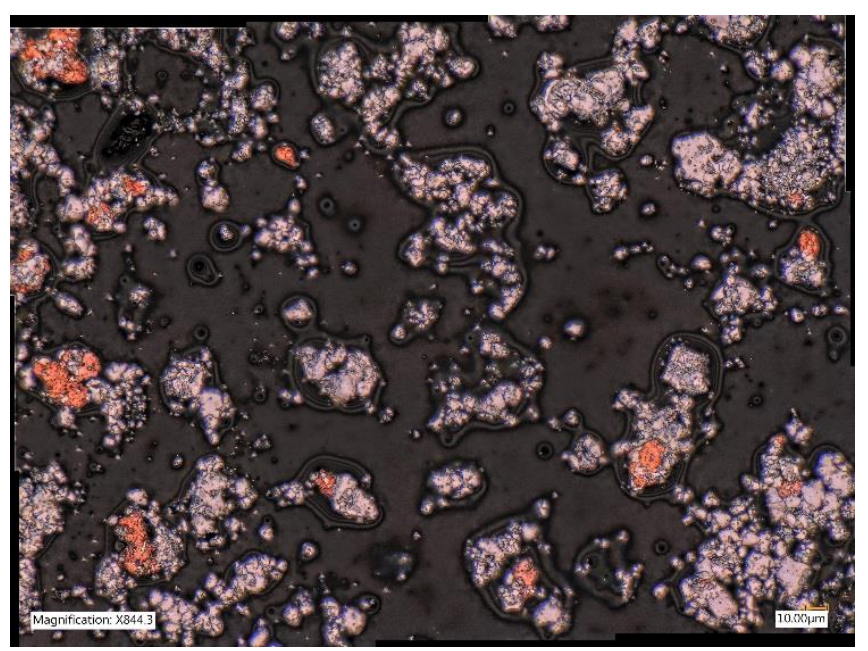

c) FM A particles, 844x magnification

Figure 2. Digital microscope images of solid particles in the FMs. Elements present are determined from their color, in combination with the XRF results. 


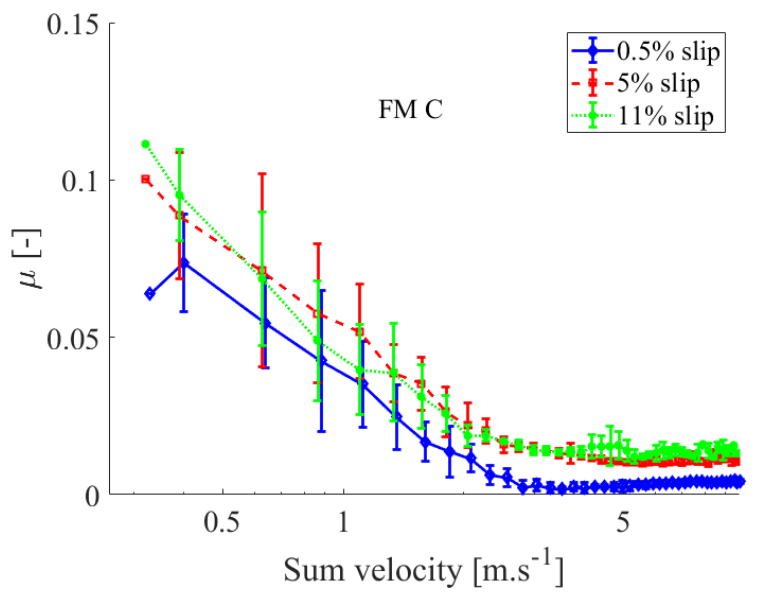

a)

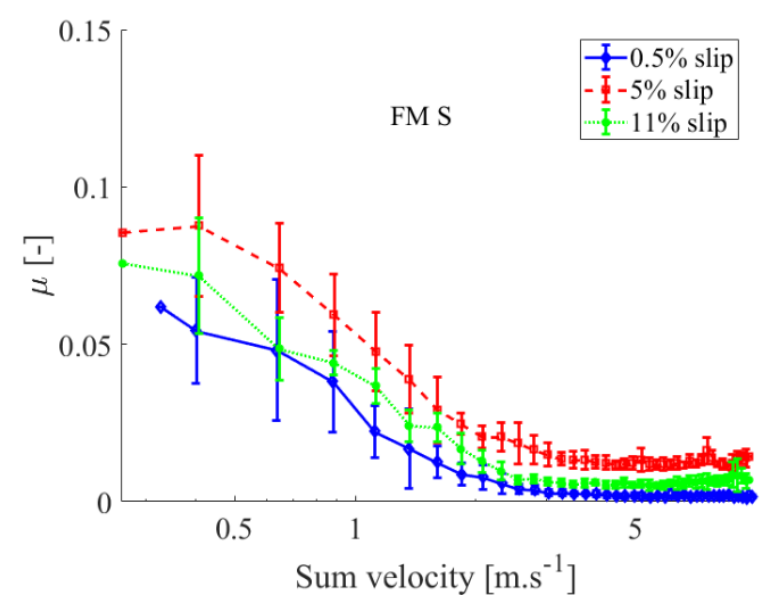

b)

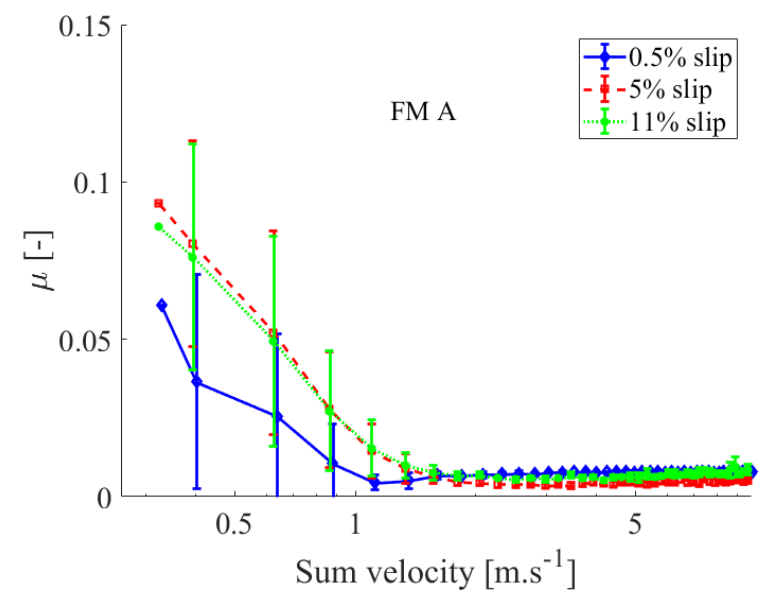

c)

Figure 3. Comparison of twin-disk results for Stribeck curves with fully formulated FMs at low, high and extreme values of slip for fully flooded conditions.

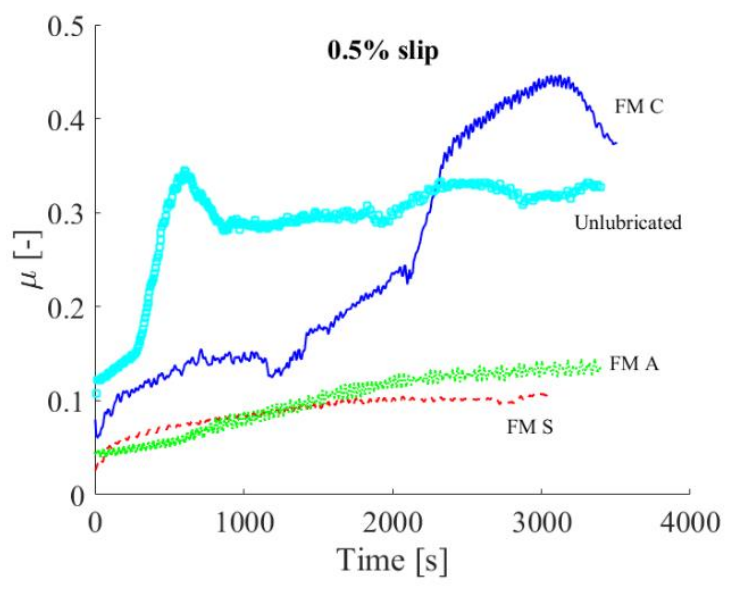

a)

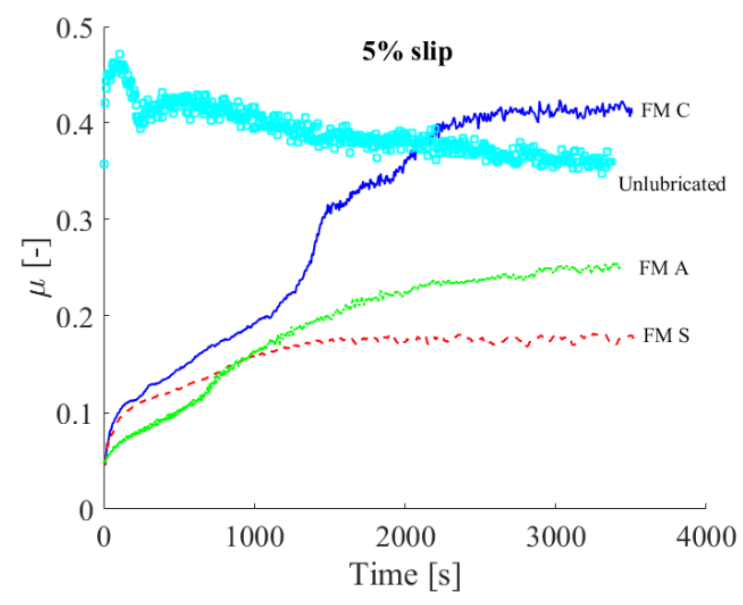

b)

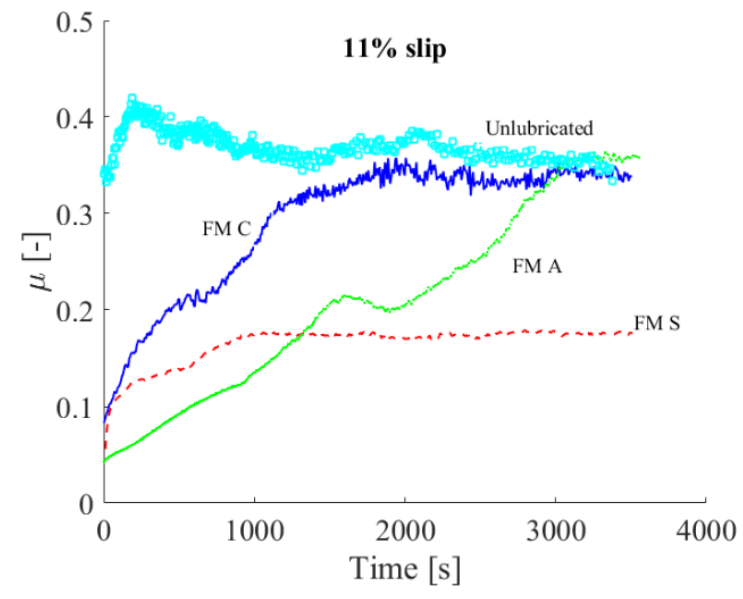

c)

Figure 4. Friction tests with $40 \mu \mathrm{L}$ of FM applied to the contact followed by running for 1 hour and in unlubricated conditions, $\mathrm{p}_{\mathrm{m}}=532 \mathrm{MPa}, \mathrm{u}_{\mathrm{s}}=2 \mathrm{~ms}^{-1}$ 


\subsubsection{Layer of Solid Particles}

In the real application the FM is spread out over a long distance, leaving only a thin layer with primarily solid particles on the rail (Suda et al., 2005). This suggests that the carrier of the FM has a limited influence on friction, i.e., the persistence of a hydrodynamic film can be neglected. To reduce the contribution of the fluid carrier on friction in the tests, pastes with high concentration of solid particles were prepared by centrifuging the fully formulated FM (10 hours at $40^{\circ} \mathrm{C}$ and $\left.11000 \mathrm{rpm}\right)$. The tests with these pastes were done at $0.5 \%, 5 \%$ and $11 \%$ slip and friction was measured over two sequences varying the sum velocity from 0.2 to $2 \mathrm{~m}$ $\mathrm{s}^{-1}$ and back. Due to the lack of fluid carrier, the results for these Stribeck tests did not show any lubrication transitions like in the fully formulated case, but rather showed an influence of rolling distance. To further investigate this influence, three tests were done with each FM. Each test had a total rolling distance of $1000 \mathrm{~m}$. The first and second tests were done at $0.5 \%$ slip with a constant sum velocity of 0.5 $\mathrm{m} / \mathrm{s}$ and $2 \mathrm{~m} / \mathrm{s}$, respectively. The third test was done at higher slip and velocity: $5 \%$ and $2 \mathrm{~m} / \mathrm{s}$. The disks were supplied with a thick layer of particle paste at the start of the tests. The results are shown in Figure 5, where friction is plotted against rolling distance. For the tests at $0.5 \mathrm{~m} . \mathrm{s}^{-1}$, a sine wave originating from the geometry of the disks was removed by filtering. For all tests an approximately linear dependency on rolling distance is seen after running-in. For FM C, a lower sum velocity seems to increase friction with the same rolling distance, while slip does not seem to have an influence. For FM S, slip has the largest influence on friction. For FM A, increasing the sum velocity decreases friction. When slip is subsequently also increased, friction increases again. The reduction in friction with sum velocity for FM C and FM A suggests the ability to form a protective layer in the first phase of the test, which is subsequently consumed over time. The rate of consumption is dependent on both slip and velocity. For FM S, there is no indication of the formation of a protective layer. The friction is mainly influenced by the

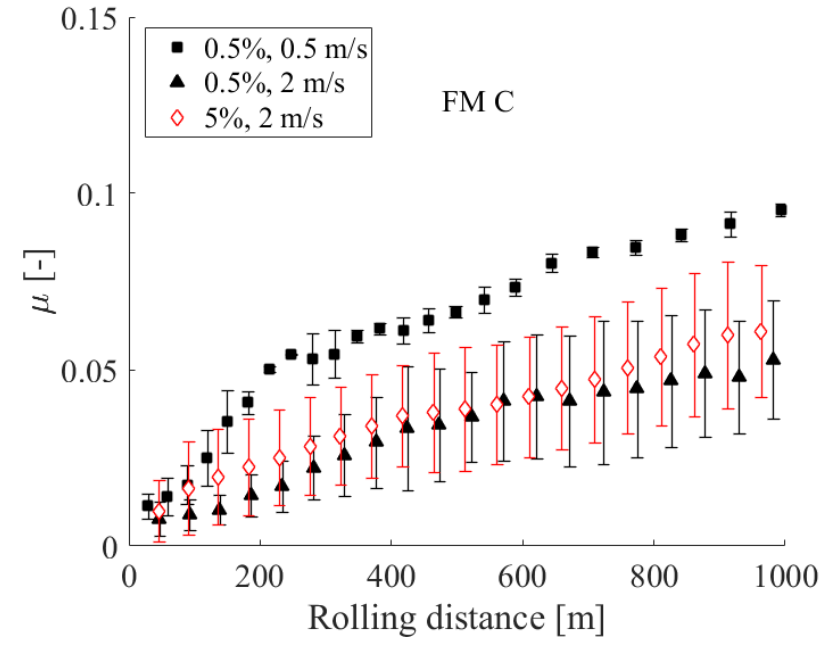

a)

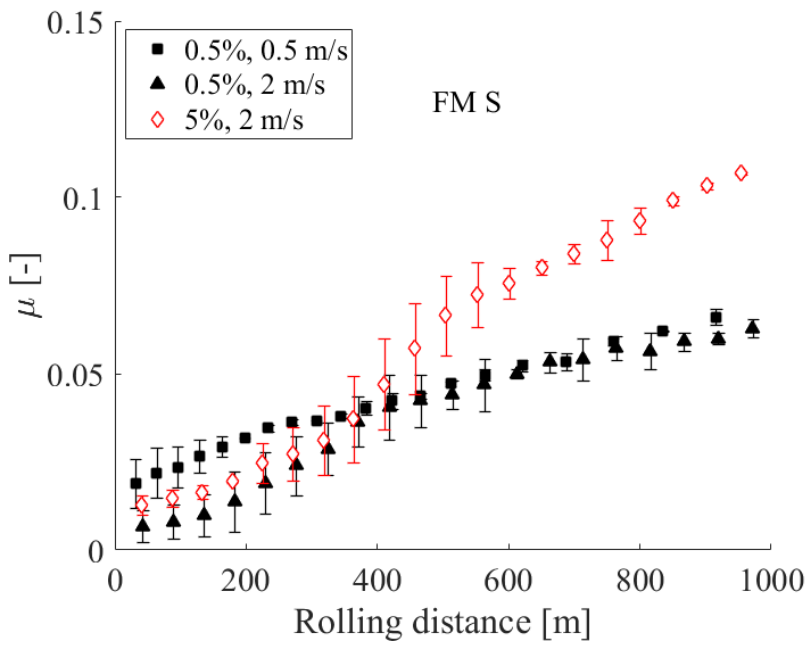

b)

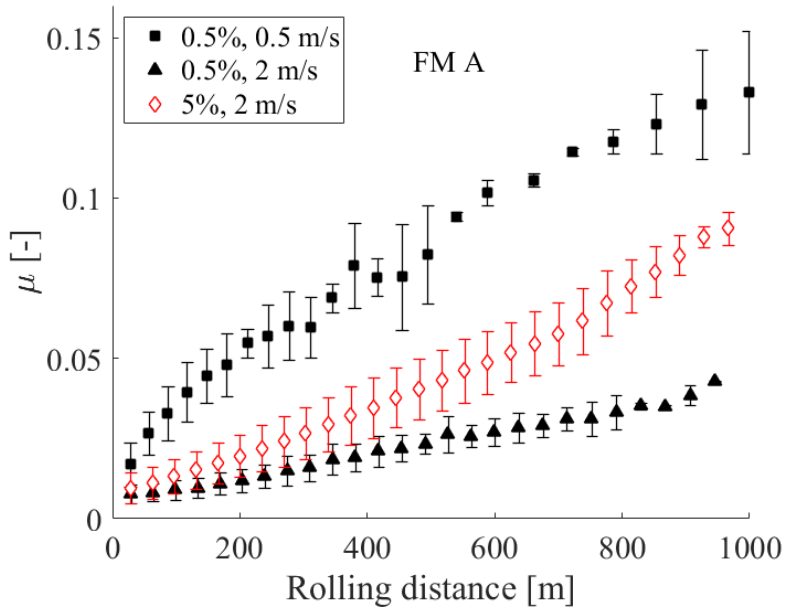

c)

Figure 5. Friction against rolling distance for all FMs. Sum velocity and slip were varied. $\mathrm{F}_{\mathrm{N}}=444 \mathrm{~N}$. 
abrasive action of the particles in the contact. These results support the hypothesis that the frictional mechanism for FM C and FM A relies on the adhesion of a protective layer, while the mechanism for FM S is based on abrasion. While one might expect an effect of sliding distance for FM C and FM A based on the hypothesis that they form a protective film, one could also consider the protective film as a "viscous" layer consisting of a paste with a small amount of base oil and a large number of particles. This allows the layer to flow without a lot of wear and the problem becomes more a side flow problem rather than a classical sliding wear type of problem (Van Zoelen et al., 2009).

The rolling distance can be translated to the number of wheels passing a rail section. The level of friction for FM C and FM A could then be predicted based on the number of wheels, their geometry and the sum velocity, which can be monitored. However, in future research here also the effect of normal load should be included, as a higher load may result in a higher wear rate of the protective layer. If this effect could be included, a step can be made towards a stable system which is conditioned based on the number of passing wheels for FM A and FM C.

\subsection{SURFACE CHARACTERIZATION}

Wear and friction are closely related and typically from the type of wear observed also conclusions regarding the driving frictional mechanism can be drawn. To validate the friction mechanisms proposed, the surfaces are analyzed after testing with fully formulated FM and solid particle pastes. For this, the wear scars resulting from the sum velocity tests with fully formulated FM at all values of slip and with particle paste at $11 \%$ slip were measured using a confocal microscope. As an example, images of a part of the cleaned wear tracks after the tests with fully formulated FMs at $0.5 \%$ and $11 \%$ slip are shown in Figure 6 . The disks were cleaned by putting them in a beaker with isopropanol in an ultrasonic bath for 5 minutes. The grooves found in the surfaces are of the order of microns in width. For FM C, there is no significant difference between the wear tracks at $0.5 \%$ and $11 \%$ slip. For FM S, the surface is very irregular after the test at $11 \%$ slip, which points to an increase in wear by abrasion at a higher slip. The wear track after a test at $11 \%$ slip with FM A shows some color difference, which is probably the remains of a protective copper layer after cleaning the surface. This is not seen in the wear track at $0.5 \%$ slip. In Figure 7 , the wear tracks for the tests with particle pastes at $11 \%$ slip are shown. For FM C, a layer of graphite with copper particles can be seen, which is not seen after the fully formulated tests. For FM S, the surface looks less irregular than after the fully formulated test shown in Figure 6. The surface for the test with FM A looks similar to the test with fully formulated FM.

To check if indeed a protective layer is formed during tests with FM A, another wear track of a test with FM $\mathrm{A}$ is shown in Figure 8. In this case, only the excessive FM on the side of the wear track was removed. A copper layer can be clearly identified from the image. The thickness of this layer is a few microns, validating the presence of a copper layer.

Wear rates were determined by measuring the volume loss of one of the disks after a test and the results can be found in Table 7 . It can be seen that an increase in slip generally does not result in a significant change of the wear rate. This shows that slip can be increased in the contact without significantly increasing the wear rate of the surface. This stable wear rate allows for a good prediction of the wear behavior with varying slip condition and therefore the lifetime can be predicted accurately when a FM is added to the contact.

Wear rates for the solid particle tests at $11 \%$ slip were also obtained and are also shown in Table 7 . After tests at $11 \%$ slip with the solid particle pastes, wear is a factor of 1.5 to three higher than for the fully formulated FMs at $11 \%$ slip. This is attributed to an increase in wear action of the particles due to the absence of a significant amount of oil.

For all cases, FM S caused the highest wear rate, which can be related to the hardness of the particles present in the FMs: the silica in FM S is very hard compared to copper and aluminum in FM C and A. This is in line with the hypothesis that the friction stabilization is based on adhesion for FM C and FM A, while it is based on abrasion for FM S

\begin{tabular}{l|l|l|l|l}
\hline & $\begin{array}{c}\text { FM 0.5\% slip } \\
{\left[\mathbf{m m}^{3} / \mathbf{N m}\right]}\end{array}$ & $\begin{array}{c}\text { FM 5\% slip } \\
{\left[\mathbf{m m}^{3} / \mathbf{N m}\right]}\end{array}$ & $\begin{array}{c}\text { FM 11\% slip } \\
{\left[\mathbf{m m}^{3} / \mathbf{N m}\right]}\end{array}$ & $\begin{array}{c}\text { Particles 11\% } \\
\text { slip }\left[\mathbf{m m}^{3} / \mathbf{N m}\right]\end{array}$ \\
\hline FM C & $3.6^{*} 10^{-5}$ & $2.1 * 10^{-5}$ & $3.0^{*} 10^{-5}$ & $4.4 * 10^{-5}$ \\
\hline FM S & $1.0 * 10^{-4}$ & $8.8 * 10^{-5}$ & $5.38^{*} 10^{-5}$ & $1.3 * 10^{-4}$ \\
\hline FM A & $4.1 * 10^{-5}$ & $4.7 * 10^{-5}$ & $6.9 * 10^{-6}$ & $2.3 * 10^{-5}$ \\
\hline
\end{tabular}

Table 7. Wear rates of twin-disk tests with fully formulated friction modifier and solid particle pastes 

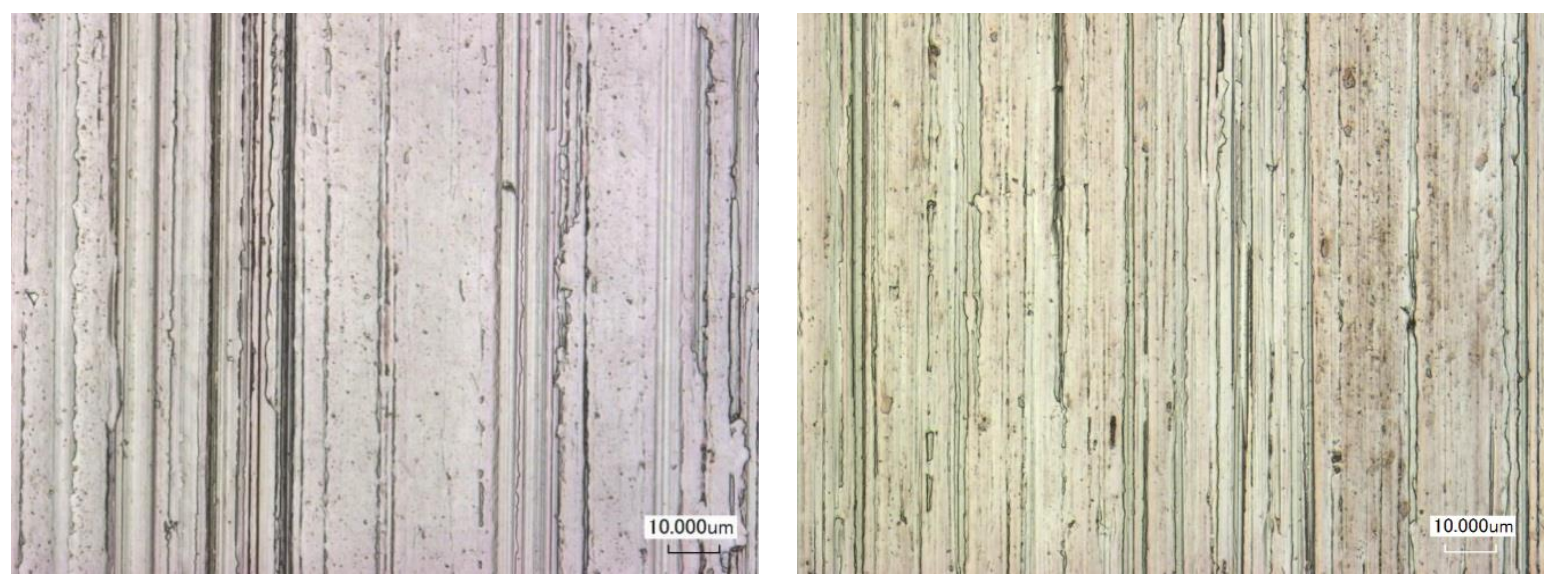

(a) FM C
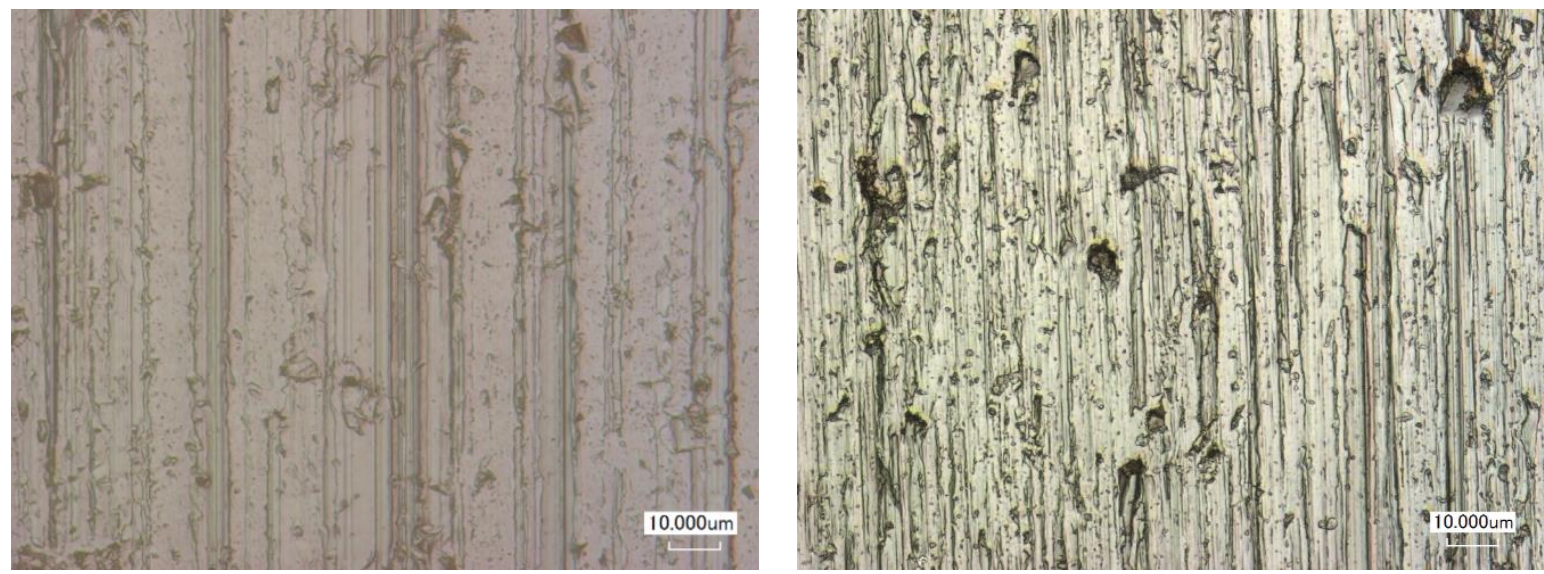

(b) FM S
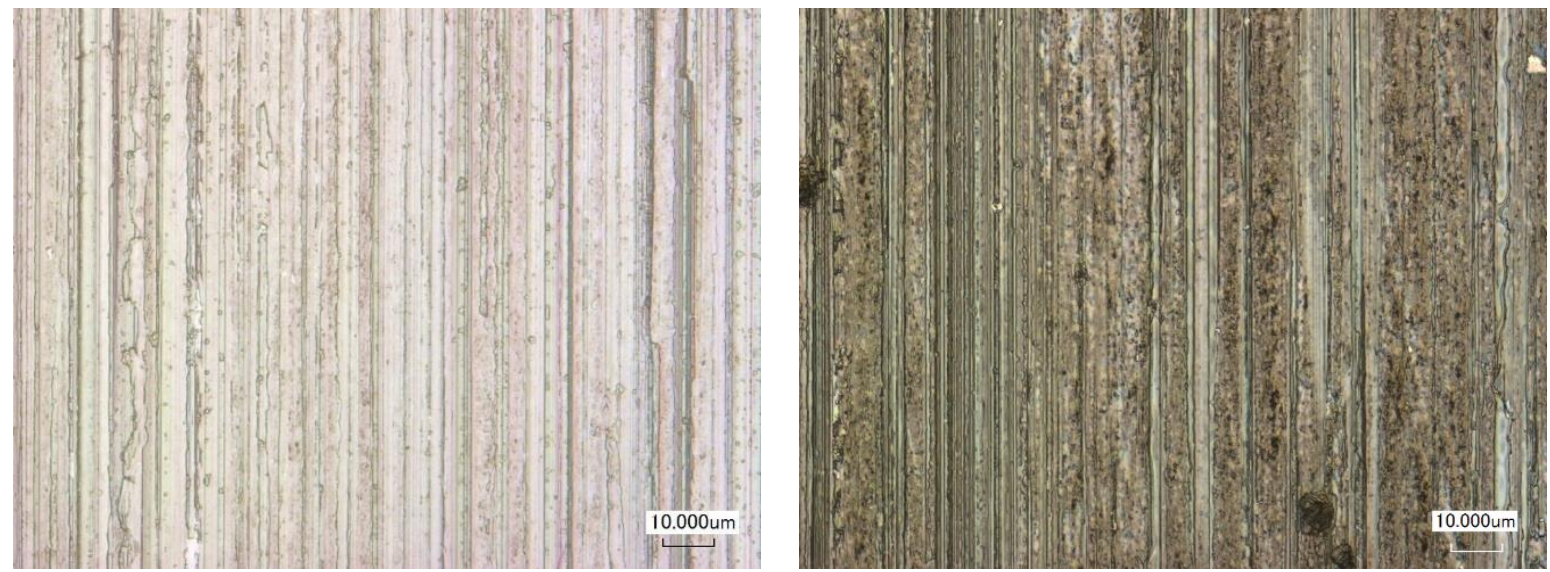

(c) FM A

Figure 6. Wear tracks after twin-disk tests with fully formulated FM at $0.5 \%$ slip (left) and $11 \%$ slip (right), 2000x magnification, image size $140 \times 105 \mu \mathrm{m}$. 


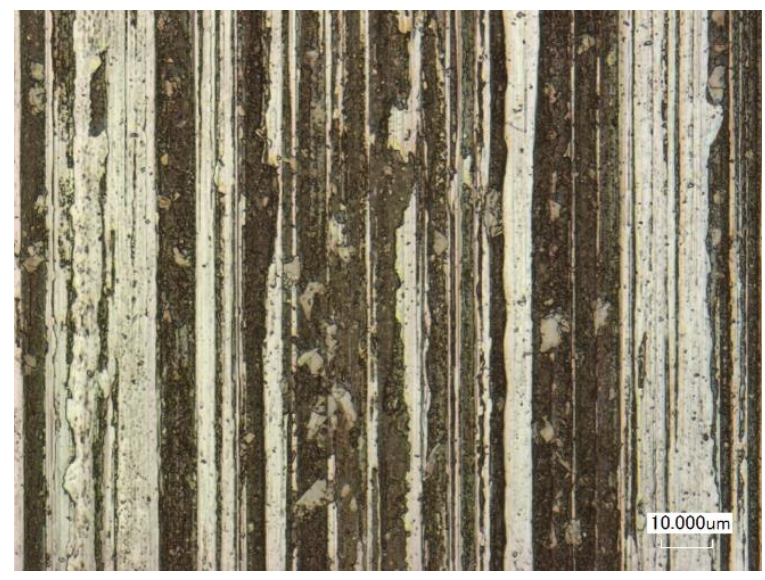

(a) FM C

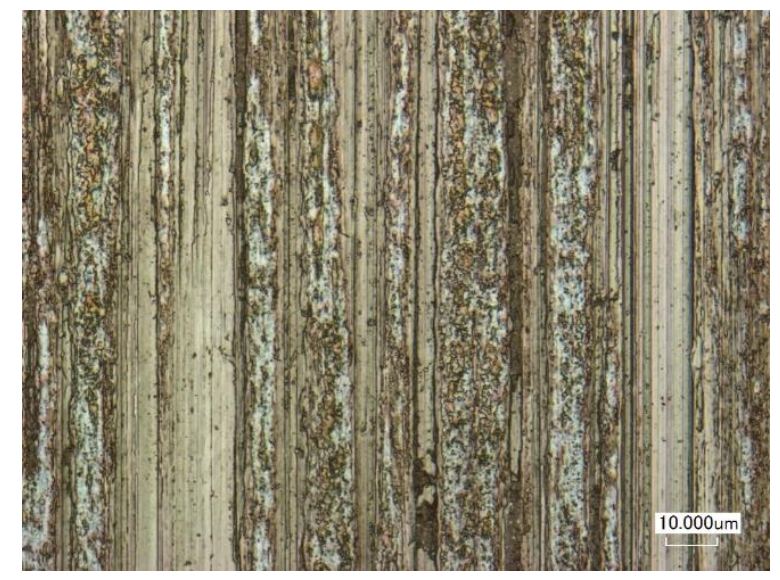

(b) FM S

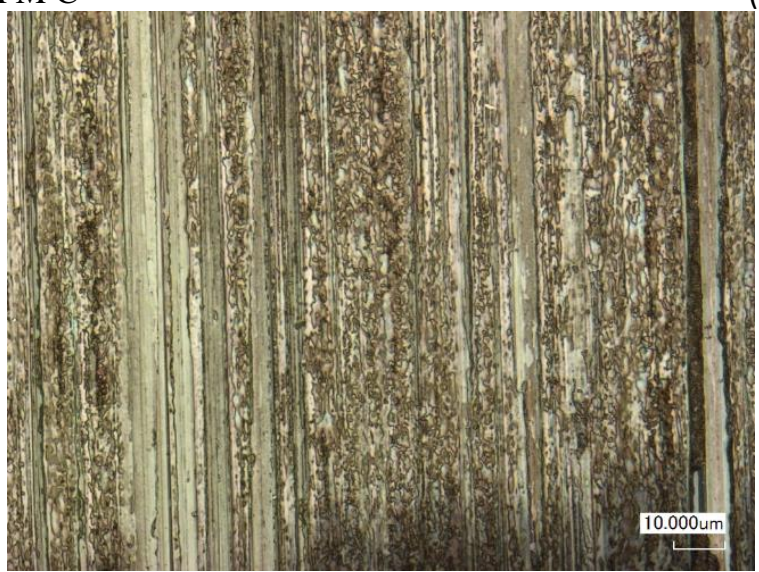

(c) FM A

Figure 7. Wear tracks after twin-disk tests with particle pastes at 11\% slip, 2000x magnification, image size 140x105 $\mu \mathrm{m}$.

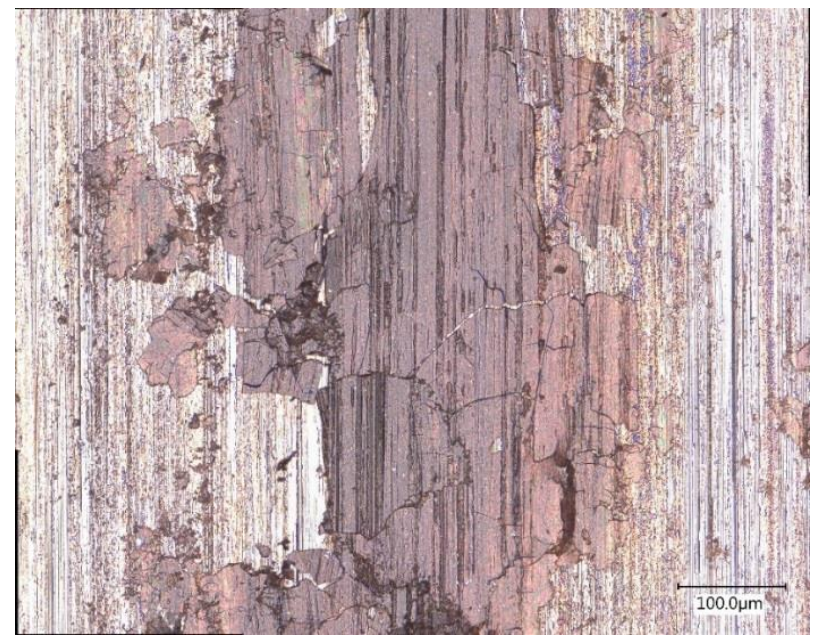

Figure 8. Wear track covered with copper after a 2-disk test with FM A, $\mathrm{v}_{\mathrm{s}}=2 \mathrm{~m} \cdot \mathrm{s}^{-1}, \mathrm{~F}_{\mathrm{N}}=444 \mathrm{~N}$, slip=5\%. 


\section{CONCLUSIONS}

A FM consists of a fluid carrier with particles. The fluidity makes it possible to spray but it also initially forms a full lubricant film which carries the particles into the contact. This full film lubrication leads to a very low friction and loss of traction and therefore should be avoided at all times. Generally, small amounts of FM are applied to the wheel-rail contact and after application of FM, starvation occurs shortly after application reducing the film and increasing friction leaving only a film/layer formed by particles.

For FM C (graphite, copper) and FM A (aluminium, copper), this layer of particles is based on the formation of a protective layer adhering to the surface. The particle layer is sheared by slip and squeezed by pressure (normal load) which reduces its thickness. The result is an increase in friction ultimately up to approximately $\mu=0.4$, which is comparable to unlubricated friction values. The type of particles dominate the frictional properties and the time interval in which a level of sufficient friction is reached and maintained. The rate of consumption of the layer is dependent on both slip and velocity. The protective film can be considered as a "viscous" layer as some base oil will still be present. Increasing slip accelerates the consumption of the layer leading to friction values equal to dry friction for FM A and FM C. With FM C a coefficient of friction of 0.4 is obtained for all values of slip. FM A requires a slip value higher than $0.5 \%$ to reach a friction level above $\mu=0.2$. At $11 \%$ slip, the coefficient of friction increases to the unlubricated value of $0.3-0.4$. The consumption of the particle layer is mainly influenced by sum velocity and is approximately linear with rolling distance. With this relationship, it is possible to predict reapplication intervals of FM to keep friction as stable as possible within a predefined range. As a consequence, the wear behavior of a rail can also be predicted.

For FM S (silica), there is no indication of an adhesive layer that protects the surface. The friction for FM $S$ is mainly influenced by the abrasive action of the solid particles, which are embedded in the surface. FM S quickly gives a stable friction level of 0.2 but the slip must be higher than $0.5 \%$ to reach this. Due to the abrasive nature of the particles and the absence of a clear consumption, it is more complex to predict reapplication intervals accurately for FM S.

The abrasive nature of the particles in FM S does cause a higher amount of wear than when a protective layer is formed for FM C and FM A.

From the above results, an abrasive FM, like FM S, can be regarded as the best choice to stabilize friction, however this comes at the cost of considerable wear. A final choice for a FM will thus be dependent on the situation and will typically be a consideration between friction and wear performance of a FM.
It is expected that the normal load and the steel properties will have an influence on the formation of a protective layer. It is recommended to investigate this further.

\section{ACKNOWLEDGEMENT}

This research was carried out under project number T91.1.12475c in the framework of the Research Program of the Materials innovation institute M2i (www.m2i.nl). The authors would like to thank the Dutch Rail Infrastucture owner ProRail for their support and Dr. I. Shevtsov for his valuable advice in the project.

\section{REFERENCES}

Arias-Cuevas, O. (2010). Low adhesion in the wheel-rail contact: TU Delft, Delft University of Technology.

Arias-Cuevas, O., Li, Z., Lewis, R., \& Gallardo-Hernández, E. A. (2010). Rolling-sliding laboratory tests of friction modifiers in dry and wet wheel-rail contacts. Wear, 268(3-4), 543-551. doi:http://dx.doi.org/10.1016/j.wear.2009.09.015

Beagley, T., \& Pritchard, C. (1975). Wheel/rail adhesionthe overriding influence of water. Wear, 35(2), 299-313.

Chiddick, K. S. (1994). Friction modifiers: Google Patents.

Cotter, J. (2004). US Patent 6,759,372.

DeBlase, F. J., Madabusi, V. K., Ferrarotti, S., Gaenzler, F., Migdal, C. A., \& Mulqueen, G. (2013). Friction Modifier Composition for Lubricants: US Patent App. 13/780,511.

Dhoke, R. (2013). Evaluation of Different Lubricants for Reduction of Rail-Wheel Noise and Wear. Paper presented at the International Conference on Technology and Business Management March.

Eadie, D. T., Santoro, M., \& Powell, W. (2003). Local control of noise and vibration with KELTRACK ${ }^{\mathrm{TM}}$ friction modifier and Protector ${ }^{\circledR}$ trackside application: an integrated solution. Journal of sound and vibration, 267(3), 761-772.

Fang, L., Kong, X., Su, J., \& Zhou, Q. (1993). Movement patterns of abrasive particles in three-body abrasion. Wear, 162, 782-789.

Galas, R., Omasta, M., Krupka, I., \& Hartl, M. (2016). Laboratory investigation of ability of oil-based friction modifiers to control adhesion at wheel-rail interface. Wear.

Gallardo-Hernandez, E., \& Lewis, R. (2008). Twin disc assessment of wheel/rail adhesion. Wear, 265(9), 1309-1316.

Godet, M. (1984). The third-body approach: a mechanical view of wear. Wear, 100(1), 437-452.

Hardwick, C., Lewis, R., \& Eadie, D. (2014). Wheel and rail wear-Understanding the effects of water and grease. Wear, 314(1), 198-204. 
Iwnicki, S. (2006). Handbook of railway vehicle dynamics: CRC press.

Johnson, K., Greenwood, J., \& Poon, S. (1972). A simple theory of asperity contact in elastohydro-dynamic lubrication. Wear, 19(1), 91-108.

Lewis, R., \& Dwyer-Joyce, R. (2004). Wear mechanisms and transitions in railway wheel steels. Proceedings of the Institution of Mechanical Engineers, Part J: Journal of Engineering Tribology, 218(6), 467478.

Li, Z., \& Arias Cuevas, O. (2009). An investigation on the desired properties of friction modifiers for slippery rails. Paper presented at the STECH'09, International Symposium on Speed-up, Safety and Service Technology for Railway and Maglev Systems 2009, Niigata, Japan, June 6-June 19.

Lu, X., Cotter, J., \& Eadie, D. (2005). Laboratory study of the tribological properties of friction modifier thin films for friction control at the wheel/rail interface. Wear, 259(7), 1262-1269.

Olofsson, U., Zhu, Y., Abbasi, S., Lewis, R., \& Lewis, S. (2013). Tribology of the wheel-rail contact-aspects of wear, particle emission and adhesion. Vehicle System Dynamics, 51(7), 1091-1120.

Popovici, R. I. (2010). Friction in wheel-rail contacts: University of Twente.

Sin, H., Saka, N., \& Suh, N. (1979). Abrasive wear mechanisms and the grit size effect. Wear, 55(1), 163-190.

Suda, Y., Iwasa, T., Komine, H., Tomeoka, M., Nakazawa, H., Matsumoto, K., . . Kishimoto, Y. (2005). Development of onboard friction control. Wear, 258(7), 1109-1114.

T. Ferreira, W., Rasband. (2012). ImageJ User Guide. Van Zoelen, M., Venner, C., \& Lugt, P. (2009). Prediction of film thickness decay in starved elastohydrodynamically lubricated contacts using a thin layer flow model. Proceedings of the Institution of Mechanical Engineers, Part J: Journal of Engineering Tribology, 223(3), 541-552. 